\title{
Values: \\ The Pandora Project
}

This chapter focuses on the values of professional practices: on how thinking and working like a professional means caring about the things a professional cares about - and thus how learning to think like a professional means learning to value the things professionals think of as important, interesting, and meaningful.

The chapter begins by looking at The Pandora Project, an epistemic game I developed with a team of researchers at Harvard University, including Kris Scopinich, Chris Braiotta, and Victoria Martins. ${ }^{1}$ In the game, players become high-powered negotiators, deciding the fate of a new biomedical breakthrough. Along the way, they learn about biology, international relations, and mediation.

The game is based on a real medical controversy: the ethics of transplanting organs from animals into humans. After a brief overview of science of xenotransplantation, the chapter describes a study of what happened when a class of high school students played the game. The study shows how this epistemic game motivated adolescents to develop the kind of skills, knowledge, and values they need to succeed in the digital age. 


\section{Of Pigs and Men}

$\mathrm{X}$-Gen is a leading global pharmaceutical company with world headquarters in the Republic of Swindonia. Researchers at the company have been working for over a decade to make it possible to transplant organs from one species to another-a technique known as xenotransplantation. Yesterday, X-Gen's scientists announced that they are ready to begin clinical trials on humans at their research center in the capital city of Hoggopolis.

Their announcement created a firestorm within the scientific and medical community. Proponents argue that xenotransplantation might end the shortage of organs for patients suffering from late-stage organ failure who need transplants to survive. Opponents say there are too many potential problems associated with taking organs from one species-X-Gen plans to use pigsand transplanting them into humans. Not least is the potential risk that a virus that flourishes in pigs could infect the human recipient and be transmitted from that patient to the general public, causing an epidemic. It is clear to the scientific community that this is a possible risk. But no one knows how likely such a scenario is.

Thus begins The Pandora Project. The scientists of Swindonia aren't sure how likely the dire scenario of global pandemic from xenotransplantation might be-and neither are scientists in the real world. X-Gen and Swindonia don't exist, but the organ donor shortage and the risk of diseases that migrate from one species to another are all too real. Each year more than six thousand people die in the United States waiting in vain for an organ transplant. Xenotransplantation offers the promise of being able to "grow" donor organs on demand, but there are obvious ethical concerns. Animal donors would be sacrificed to make organs available for human patients, and while alive, the animals would have to be kept in isolation and in sterile conditions-which some say would be cruel to the most likely donor species, primates and pigs, which are extremely social animals. ${ }^{2}$

We know that it is possible for a virus to migrate from animals to humans. It has happened in recent years with SARS (severe acute respiratory syndrome) and the avian flu even without transplanting animal organs into a 
human patient and suppressing the recipient's immune system with drugs to prevent organ rejection. The recent SARS epidemic caused over 750 deaths, with cases reported in over 20 countries worldwide. As of January 2006, the more recent avian flu had only 85 deaths in five countries-but more than half of the people who contracted the disease died as a result. And, of course, it is now widely believed that HIV, the virus that causes AIDS and has claimed some 25 million lives since 1981, came from a similar virus in chimpanzees. ${ }^{3}$ Whatever happens, decisions about xenotransplantation are decisions about life and death on a large scale.

Despite these very real concerns, development of the science of xenotransplantation continues. In 2001 the Pontifical Academy for Life in the Vatican announced that it does not object to the transplantation of animal organs into humans. The US Food and Drug Administration (FDA), which has regulatory oversight in the United States for xenotransplantation, has developed guidelines for clinical trials using the procedure. In 2004 the World Health Organization Resolution on Human Organ and Tissue Transplantation urged member states to allow xenotransplantation "when effective national regulatory control and surveillance mechanisms overseen by national health authorities are in place." ${ }^{\prime 4}$

Globalization isn't only about trade in goods and services, and in the era of AIDS and SARS and avian flu, part of being an informed citizen means learning to make decisions about complex, science-based public health issues. Part of thinking in innovative ways in a global economy is learning to assess the risks and rewards of new inventions and innovative solutions — solutions to old problems and new ones. ${ }^{5}$ And The Pandora Project is an epistemic game designed to help players do just that.

\section{The Science of Xenotransplantation}

To understand the potential risks and potential benefits of xenotransplantation, you have to know something about genetics, epidemiology, and immunobiology. You have to understand that the human immune system protects the body from potentially harmful microorganisms and cancerous cells using antigens: proteins that identify cells as belonging to the body. When 
foreign antigens are detected, the body's immune response begins. Phagocytic cells_-more commonly known as white blood cells_aided by antimicrobial proteins, try to surround, absorb, and destroy the foreign cells.

The human immune response system matters in understanding xenotransplantation because any transplanted organ - whether from a human or animal donor - is by definition a foreign substance to the body, and the body's natural defenses work to reject it. Before transplantation, donor organs are typed-that is, their antigens are matched as closely as possible to the antigens of the potential recipient—but drugs are still needed to prevent the recipient's immune system from attacking the transplanted tissue. These immunosuppressive drugs make transplant recipients more likely to catch colds, flus, and other diseases that pass from person to person. More alarmingly, though, if the donor organ carries an undetected virus or bacteria, the recipient's suppressed immune system is less able to fight it off.

So, on one hand, it might seem that xenotransplantation, if feasible, would be safer than human organ donation. After all, the animals could be raised in completely sterile conditions. The genetics of their organs could be matched as closely as possible to the recipients by breeding them for particular combinations of antigens on their cells that would match the host. And perhaps best of all, because different species have different genes, they often are affected by different viruses. The things that would make a pig sick often have little or no effect on a human, and vice versa.

Ah, but there's the rub. The particular danger of xenotransplantation is that a virus or bacteria that is harmless to pigs (or other donor animals) could be introduced into a human host. The immunosuppressive drugs would make that host a perfect breeding ground: The person would have little ability to fight off the new bacteria or virus, and it would be free to multiply, perhaps mutating into a form that can cause human disease. In fact, it could mutate into a form that would not only infect a human host, but could also pass directly from one person to another without having to be introduced through a transplant. The result could be a worldwide epidemic.

Understanding the costs, benefits, and risks of xenotransplantation thus depends on understanding the science behind it. But assessing xenotransplantation means grappling with the moral dilemmas that this new technology raises. 
The procedure would require careful breeding and maintenance of genetically altered animals raised in sterile conditions, which would be extremely expensive. Every dollar spent on xenotransplantation would be money not spent on less expensive procedures, or on investment in public health measures more generally. The money spent researching the technique would be money not spent trying to develop other solutions to the organ donor shortage or cures for other diseases. If the procedure works, most of the patients who benefit would be from wealthy countries. If an epidemic breaks out, the victims who suffer most would be from countries without adequate healthcare or the infrastructure to support a massive public health effort to prevent the spread of a new disease. Even within wealthy countries, the benefits of the procedure would accrue to individuals, but the risks would be borne by everyone. Who should decide whether the risk is worthwhile?

\section{MUTUAL GAINS NEGOTIATION}

If and when xenotransplantation researchers want to work with human patients, science will play an important role in deciding whether and how to proceed, but in the end any decision will be reached through some process of negotiation. Decisions will be made by interested parties working together-and against one another-to influence regulators at the FDA and its equivalents in other countries. Central to that process will be people representing the interests of biotechnology companies developing the procedure, the World Health Organization and other nongovernmental organizations, animal welfare groups, patients' rights advocates, medical associations, and others. And these different interest groups will be represented by people skilled in the ways of negotiation, mediation, and dispute resolution.

In The Pandora Project, players take on the role of negotiators for groups in Swindonia interested in xenotransplantation, and the game they play in these roles is modeled on the training of professional negotiators as developed by the Harvard Program on Negotiation.

The Program on Negotiation emphasizes a particular way of thinking about negotiating known as the mutual gains approach, described in the book Getting to Yes by Roger Fisher and William Ury. ${ }^{6}$ Unlike some theories of negotiation, 
which emphasize things like making your adversaries in the negotiation physically uncomfortable (perhaps by seating them with the light shining in the faces) or playing "good cop/bad cop" with a member of your negotiating team, the mutual gains approach is based on the idea that different stakeholders in a dispute have legitimate but conflicting interests. In this approach, no side is necessarily in the right or in the wrong. Rather, the goal of a negotiation is to reconcile different interests in a way that satisfies the groups in the dispute.

The approach is called "mutual gains" because the idea is to find ways for the parties to trade across differences - that is, for each side to give up something that does not mean much to it in order to get something that it cares about more. To do that, a mutual gains negotiator has to focus on the parties involved in a problem, understanding their needs and analyzing how different solutions impact their legitimate interests. The negotiator constructs a conflict assessment: a matrix that systematically identifies the different issues in a dispute and the positions of the different stakeholders on those issues. Part of the conflict assessment is identifying each group's BATNA, or best alternative to a negotiated agreement. A group's BATNA represents what the outcome would be for it if the negotiation fails. For any party in a dispute, a negotiated agreement has to be better than its BATNA to make the agreement acceptable. Otherwise the group would be better off walking away from the negotiation.

In this way, the conflict assessment prepares the negotiator to trade across issues with different values to different stakeholders, looking for an outcome that is better than the BATNA of enough groups in the dispute to produce a negotiated settlement. And, of course, if more than one resolution is possible, the mutual gains negotiator tries to find the arrangement that will get the most for his or her side.

In other words, mutual gains negotiators are professionals who specialize in finding innovative solutions to complex social, economic, and interpersonal conflicts. Theirs is a valued profession, with the skills and knowledge needed to deal with contentious issues like clinical trials of xenotransplantation.

\section{GETTING TO GETTING TO YES}

To learn about xenotransplantation in The Pandora Project, players need to think like mediators. They need to learn about BATNAs and conflict assessments and 
the other concepts of mutual gains negotiation: the knowledge of the profession. They need to use these tools to trade across differences: the key skill of mutual gains negotiation. And they need to develop the mutual gains perspective of thinking about conflict in terms of legitimate conflicting interests and resolution as a means to reconcile those different interests in a way that satisfies the groups in the dispute: that is, they need to think like negotiators.

Like most professionals, negotiators learn though a practicum. The practicum for mutual gains negotiation is based on simulated negotiations in which negotiators in training take on the roles of the stakeholders in fictitious disputes and then debrief about their experiences. A simulated negotiation identifies key issues in a dispute and for each issue specifies a set of possible outcomes. For example, in a contract negotiation between a mine workers' union and the owners of a coal mine, the issues might be retirement benefits and layoffs. For layoffs, the possibilities might include laying off workers whenever the company wants, laying off only the most recently hired workers, or not laying off any workers. For retirement benefits, the possibilities might include continuing the current pension plan, continuing it only for existing employees, or divesting the pension plan entirely.

The players representing stakeholders in the dispute receive a confidential point score for each option, representing the value of that outcome to their stakeholder. These utility points vary for each stakeholder. In the mine workers' contract negotiation, the company might receive 100 points if it can lay off workers at will and lose 100 points if it bargains away the right to lay off workers, because temporary layoffs are one of the ways that this company responds to seasonal fluctuations in the price of coal. The union might receive 75 points if the contract protects workers from layoffs, but lose only 20 points if the company can lay off workers as long as the newest hires get laid off first because the union's primary interest is to protect its most senior members. In other words, the company, in this example, cares more about layoffs than the union does, and this is reflected in the fact that the company's utility point scores are larger (both positive and negative) than the union's on this issue.

At the same time, the union may care more about pension benefits than the company does. This would be reflected in more extreme utility point scores on the pension options for the union than for the company, and would make it 
possible for the two sides to trade across differences. If the union accedes to the company's wishes on layoffs and the company accommodates the union's interests on pensions, each side gains more than it loses, and it may be possible to find a mutually acceptable contract.

In other words, each stakeholder gets a high score in utility points for a different set of outcomes to the issues in dispute. The negotiation takes place as the stakeholders trade across the issues in dispute, trying to find a set of options that will satisfy the needs of all participants-that is, negotiators try to find an agreement that will get enough of the stakeholders a score higher than their BATNA (which is also represented with a utility point score) to be mutually acceptable.

Of course, this process is intensely competitive, since the goal for each side is to get a negotiated settlement that maximizes its own utility points, even if that means (as it usually does) lowering other participants' scores.

Negotiators in training prepare by constructing a conflict analysis. While each participant knows the utility point scores for his or her own side, the scores of other stakeholders are confidential, so planning a negotiating strategy requires investigating the wants and needs of the other groups involved in the dispute. When the negotiation is concluded, the negotiators debrief with experts, discussing their strategies, what worked and what didn't, and trying to understand the process of the negotiation from a mutual gains perspective.

\section{SWINDONIA CODE OF MEDICAL REGULATIONS, PART 227}

The Pandora Project, then, is modeled on a practicum for mutual gains negotiation using a simulated negotiation about xenotransplantation. The premise is that the X-Gen company has submitted a 227(e) application to the National Government of the Republic of Swindonia for permission to begin clinical trials in xenotransplantation as a Class V medical procedure, which Swindonia's regulations define as "any device or procedure that is of substantial importance in preventing impairment of human health, but which presents a potential, unreasonable risk of illness or injury." Concerns about the safety of xenotransplantation place it in this category. 
The national government would like to see research on xenotransplantation go forward, but has significant concerns about safety, public perception, and international reaction, should it approve the procedure for clinical trials. The government asked representatives from interested groups to meet and decide on a set of conditions under which it would be appropriate for clinical trials to proceed. Negotiations went on for several months with no resolution. X-Gen, concerned about the time the process was taking, threatened to file a lawsuit against the government for delaying regulatory approval. The government wants the issue settled, but will not grant approval without resolving the outstanding concerns, so its representatives have asked the chief negotiators from each party to meet one last time to try to reach a compromise. If these talks fail, the government will deny approval for the technology, and X-Gen will have to decide whether to bring suit in court.

Five participants are at the table:

1. X-GEN: Medical experts and researchers at X-Gen are convinced that the decade they devoted to conscientious research provides a solid foundation to move forward into clinical trials of xenotransplantation.

2. Patients' Rights Organization (PRO): $\mathrm{PRO}$ is interested in patient welfare. It understands that advances in the field of xenotransplantation will bring significant benefits to patients who are currently being treated by dialysis or respirators as well as patients on transplant waiting lists.

3. World Health Organization (WHO): WHO is particularly concerned with the question of international equity. Exposure to the risk of an epidemic is global, but access to the benefits of xenotransplantation will be restricted to countries that can afford the procedure.

4. National Government: New drugs and medical procedures in Swindonia are authorized by government regulators based on health and safety. But xenotransplantation raises concerns about safety that are hard to evaluate. The government would like to see the benefits of xenotransplantation realized but not at the cost of compromising public welfare.

5. Animal Rights COAlition (ARC): ARC is a coalition of animal rights groups that is opposed to research done on animals. It recognizes that 
in the current national climate, it is impossible to ban animal research entirely, but it wants to limit the impact of research on animal subjects.

The issues being considered cover many of the key questions and concerns about xenotransplantation: Should recipients be subject to quarantines or a lifetime of monitoring by regular physical examinations and tissue sampling? If something does go wrong, what outcomes will indicate that the procedures should stop? Should X-Gen be responsible for paying for a response to possible outbreak? Under what conditions will donor animals be kept? Will X-Gen or the government fund public health initiatives in developing countries to provide a response in case of an epidemic? Will the cost of xenotransplantation for citizens in developing countries be subsidized? Should X-Gen or the government provide research funds for less expensive solutions to the organ donor shortage or more general public health initiatives to reduce the incidence of more widespread diseases?

The government is eager to see the proceedings resolved, and hopes that the meeting results in a unanimous consensus. However, it is willing to accept a set of options that four of the five stakeholders sitting at the table agree on, as long as both X-Gen and the government are in agreement with the proposal.

And so the negotiation begins.

\section{“Pigs, Pigs, Pigs"}

To find out what happens when young people play a game based on the training of professional mediators, we studied one class of fourteen high school students who played the game over two weeks of class time: a total of nine hours of game play. The students were enrolled in an ethics class at an independent school in Massachusetts, and it was the teacher's decision to play the game as part of the curriculum. ${ }^{7}$

For the study, we interviewed players before and after the game, and players wrote daily in an online journal. In the interviews players described their views on xenotransplantation and biotechnology. They completed concept maps about xenotransplantation, representing diagrammatically their understanding 
of the issues and interest groups relevant to the procedure. They responded to transfer scenarios: problems designed to see whether they were using ideas learned in the game to solve problems outside the game. And we asked them what they thought of the game, what worked well and what did not.

The game began with a multimedia introduction to the issues of xenotransplantation: a cut-scene that gave an overview of the game to come. Players took on stakeholder roles in groups of three and spent several class periods conducting a conflict assessment, using Internet links in the game to research their positions on xenotransplantation and the positions of the other stakeholders. They gathered information on genetics, epidemiology, and cell biology they needed to argue for their position. Based on their research, each stakeholder group prioritized the issues in the dispute and the various options for each one. Using these priorities, the game computed utility points for each role. Players then divided into groups of five, with each player representing a stakeholder in one of three separate negotiations. The negotiations themselves took place over three days, and the game ended with the same kind of debriefing that takes place in a negotiation practicum.

In other words, the game was modeled explicitly on the kinds of action and the kinds of reflection-on-action that negotiators in training go through in their practicum.

\section{SKILLS AND KNOWLEDGE}

It hardly comes as a surprise to learn that a game based on the training of professional negotiators helped players develop their skills in negotiation. Players needed to conduct conflict assessments to understand the positions of the various sides in the dispute, which meant gathering, reading, and making sense of detailed information about the dispute. As one player explained:

[I found] a whole bunch of legal documents that I read through about patients in terms of xenotransplantation and the government [and] where they stand on it.

Once they found information, players needed to figure out where their stakeholder stood on the issues—and equally important, what players representing 
other stakeholders were likely to do. Said one player:

We met every night before a negotiation day. We had to get everything straight—get the issues straight and figure out what we thought about everything — and we ended up meeting for like two hours that first night and talking about it and reasoning it out, like every argument with every option, and hypothesizing about who was going to support what.

Of course, skill in negotiation is not just about preparation. A mutual gains negotiator focuses on issues rather than tactics: on staying calm and negotiating based on interests rather than emotions. As in the negotiation simulations that train real negotiators, the negotiation simulation at the heart of The Pandora Project demanded the same kind of discipline. As one player said:

Our group got pretty heated sometimes ... [but] when people were upsetting me I tried to remain calm.... And I think that was really important because ... when people's voices start to raise and people get irritated and stuff like that then people get defensive. And then once you're on the defense you're not looking to compromise, you're looking to save yourself. And that's not effective.

In other words, players began to develop some of the skills of a mutual gains negotiator-which necessarily meant developing the knowledge about the professional practice, and in this case about xenotransplantation as well.

In explaining what she learned from playing The Pandora Project, one student remarked that she knew very little about xenotransplantation before the game-and, more than that, before playing the game she had naively assumed that scientific and technological advances were always good:

I had no idea what xenotransplantation was or how it could affect people in this way. So I think [the game] definitely created a better sense of awareness about "the public versus technology" and how that could affect us. I guess I always assumed that whatever [scientists] were doing to make things better was great. But I never really thought about how it was affecting us as a globe or a huge group of people. So I think [the game] made me more aware. 
Overall, 91 percent of the players we studied said they had changed their opinion about xenotransplantation during the game. The same proportion reported that they understood the process better after playing the game.

We were able to measure whether players' thinking about xenotransplantation became more complex by asking them to complete concept maps showing the people and issues involved, and how they were connected. Players completed one map before the game and another two weeks later, after the game had ended. The maps made after the game included more people and issues and 45 percent more connections among them. ${ }^{8}$

Describing the difference in his maps before and after the game, one player explained how he was thinking more deeply about the implications of xenotransplantation:

When I first did it ... I sort of just pointed out the obvious [connections] like patients, government subsidies. ... I wasn't really looking [for] more involved relationships that some groups might have with one another, or how one thing might be related to another.

In The Pandora Project, players learned about the process of negotiation, and about the science and bioethics of xenotransplantation. And as we've seen in the other epistemic games, players' new knowledge stuck because they were, as one player explained, actually using what they knew:

Through books I would probably learn the definition of xenotransplantation, what are the risks and benefits and the procedures and all these numbers. But the negotiation I actually had to live as a person that is directly interested or in, that is, deciding on an issue.... You can read all the procedures and the expected results, but you have to actually use it to realize what it is and how it works.

\section{EPISTEMOLOGY}

What tied skills as a negotiator to knowledge about negotiation and xenotransplantation in The Pandora Project was the epistemology of negotiation: the 
perspective that one takes as a negotiator, the kinds of questions a negotiator brings to a new situation, the kinds of answers a negotiator accepts, the way a negotiator justifies his or her actions.

To understand whether and how players began to think like negotiators after playing The Pandora Project, we gave them transfer scenarios: questions about issues like the differential impact of technologies in developed and developing countries, the relative importance of individual and social risks in evaluating new technologies, and the cost/benefit trade-offs of expensive technologies. ${ }^{9}$ These transfer scenarios asked players to make recommendations about fictional technological breakthroughs based on complex scientific topics that raise difficult ethical issues. For example, one scenario described a new surgical technique used in treating cancer. The procedure has a 5 percent success rate with patients for whom all other techniques have failed, but it is extremely expensive, and some people have raised concerns that it will divert resources from less expensive and more effective treatments for other diseases. The scenario asks players to describe what conditions, if any, they think should be imposed on the use of this new technique.

Before the game, one player suggested that the technique should "definitely" be developed because "diverting resources from less expensive and more effective treatments is definitely important." The player went on to explain: "It definitely says hope. .. . I think it should be developed more, and . . maybe they should be working on a technique that would be, you know, more cost effective, or I don't know." Notice that this answer is vague. What is the "it" that "says hope"? Also, the solution proposed- "working on a technique that would be, you know, more cost effective" - is essentially that the problem should be addressed by coming up with something better.

Both of these characteristics changed when the same student responded to a similar scenario after the game:

I think that the doctors are right ... to be concerned that money is going to go to this research. But I would almost be inclined to allow this treatment to continue only if [the company that is developing it is] paying for everything but no money is taken away from other techniques. Since it only has a 5 percent success rate I would be more inclined to not even mention it to 
patients.... [because] at the very end people would be really willing to do things that if they were more conscious of what was happening they might not have agreed to.

Here we see the response is more specific: The player identifies particular stakeholders (doctors, the company, patients) and the concerns they have regarding the problem. Moreover, the solution proposed is not merely to make the technique better, but one that tries to address the concerns of these stakeholders simultaneously.

Answers to these transfer scenarios showed that the game helped the players we studied think about ethical dilemmas raised by new technologies using the epistemology of professional negotiation. Players began to analyze disputes in terms of legitimate conflicting interests of stakeholders, focusing on understanding the needs of the parties affected by a problem.

In other words, the skills, knowledge, and epistemology developed in a negotiation practicum about xenotransplantation helped these players think like negotiators about other technological dilemmas.

\section{BRIAR}

Players got a lot out of The Pandora Project: skills, knowledge, and a new way of seeing the world in which to use them. Part of the reason they gained so much was that the game was fun to play. As part of the interviews, we asked what the players liked and didn't like about the game. As one player put it: "I think this really got us engaged. It really got us motivated.” Another said:

Meeting before the negotiation was kind of like this intense period of five minutes, we'd be like: "OK. You make sure you got this." "Are you all set on this? And what if they do this? Do you know what our alternative is?" And: "Make sure you don't give into this!"

And a third: "I didn't want to sit at the table and have somebody be, like: 'So how do you know that?' And be, like: 'I don't really know.' "

But what made the game powerful is that the "fun" of the game was directly related to the things that players were learning. When they finished playing, 
82 percent of the players we studied said they were interested in learning more about xenotransplantation and questions about ethics and technology. As one player said:

I think I definitely want to follow up on everything that we've done. Because it's really interesting. And it's really so powerful and so permanent in the science world that I think it would be a shame to just drop it.

In other words, this game motivated players because it made them care about what they were doing.

Now in some ways, that is not very surprising. After all, this was a game based on a professional practicum, and one of the things that a practicum has to do is help novices learn to care about the kinds of things that matter to some group of professionals. Being a professional is always hard work, and learning to think and act like a professional always means learning to care about the things you are doing. Otherwise no one would bother, and the profession would die out.

One of the ways we tested how well The Pandora Project helped players think like professional negotiators was to ask them about Briar Lockhart, a teenage girl suffering from liver disease and waiting for a donor organ. She is introduced to players as part of the opening of the game through an excerpt from a Canadian news broadcast that describes her plight. At the beginning and end of the game, we asked players whether Briar should consider accepting a xenotransplant if one were available.

Most of the players we tested changed their mind about Briar during the game. At the beginning, 82 percent said Briar should take the transplant with relatively few reservations. At the end, 45 percent recommended the transplant but only if certain conditions were met; 36 percent recommended against the transplant; the rest felt that they did not know enough to make a recommendation.

What is more dramatic, though, about the change in players' responses to Briar is the extent to which they came to value her perspective rather than their own. For example, at the beginning of the game, one player wrote:

I think that Briar should accept the transplantation. As I see it she has two options: 1 . Not get the transplantation, and turn yellower and then die. Or 2. Take a risk and get the transplantation.... There is a possibility that it 
would work out, and she would be fine, plus one pig liver. Whatever. I wouldn't get xenotransplanted for fun. But what has she got to lose? Her life ... ? She should give this a chance.

According to this player, Briar should accept a donor organ raised in a genetically altered animal because that's what he (the player) would do. The key phrase was "as I see it," and this player's response to Briar's dilemma was to see the problem from his own point of view.

After playing the game, the same player became far less certain. But the dramatic change was in the extent to which he came to care about what Briar herself thought:

I cannot make that judgment without a lot more information on the procedure and its accompanying issues. ... But I can come up with the questions I think she would need to have answered:

1. Is there a quarantine? How long? How strict? Can I see my family? How long am I going to be restricted to a hospital bed for ... ? What kind of a life would I have saved myself for?

2. What happens if the transplant works, but I get even sicker from a disease I get from the pig... ? Is this something no one will know how to deal with? What kind of a life will that be ...?

3. How much do I want to be a part of this procedure which is an experiment, when I know that the results are so unpredictable and I am so aware of the risks ...?

I guess part of me is still pretty skeptical about the whole thing. However, I think the answers to the above questions are key to the eventual decision of whether or not the transplant is a good idea. Not only do they ask for more information on the details of the operation, they also pose personal questions which are essential to the question of whether or not she should do this that can only be answered by Briar.

In other words, this player came to value someone else's perspective as much as (and in this particular case, more than) his own. 


\section{VALUES}

One of the critical values of a mutual gains negotiation is respecting the needs of different parties in a dispute. A mutul gains negotiator believes that different groups can have conflicting but nevertheless legitimate goals and objectives, and that negotiating is more effective-for the group as a whole and for the particular side he or she represents-when the problem is seen based on that respect. This is what takes what one player called the "heat" out of difficult negotiations and lets the different sides in the conflict find ways to trade across differences to find a workable solution. In the professional practice of negotiation-and in any profession-the skills, knowledge, and epistemology of the profession go hand in hand with its values.

As a result of the game, players in The Pandora Project began to respect multiple perspectives. For example, one player described why she was analyzing the transfer problems differently after the game by explaining that she now cared more about the questions of equity—about making sure that everyone involved in a decision gets treated fairly. In one of the problems, a company has genetically engineered grain that is inexpensive but infertile. So if farmers buy it (because it is cheap), they cannot save seeds from one year to plant the next. They have to keep buying seed each year. After the game, this player said:

I'm think I'm thinking a little bit ... more fairly. When I first read [this problem] ... I was like: "If they [the biotech company] made it up [i.e., invented it], they should get to do what they want with it. And the poor countries should not buy it if they don't think they're going to be able to buy it in the future." But [now I] realize, you know, in the short run, they might think: "Oh, it's a great, a great way to improve our economy ... !" And after that they could be in trouble, especially because it's a monopoly. So, I think [now] you sort of realize what can happen, and you're sort of like looking to make sure that everything is okay in the end, I guess, for everyone.

To learn to be a good negotiator, you also have to develop the values of the profession. As one player said:

I had a sense for where each of the different groups would be coming from, but I think hearing them say what they believed ... made me rethink it in a way. Animal rights always sticks in my mind because I thought she was 
going to come to the table being like: "Pigs, pigs, pigs." And then they were really about taxes and issues that I didn't really think that animal rights would be concerned about. So I think in that sense it definitely made me reevaluate everybody's position. ... Listening to each one, you put yourself in their shoes.

Another player said: "In order to do it right, you had to look at everything from everybody's point of view."

\section{Postprogressivism}

Any game is about values because playing a game always means playing a role and following the rules that role implies. In this sense, all games are ideological: They all emphasize some things as being more important than other things. Any game utilizes certain skills and not others, develops and uses some kinds of knowledge and not others. You need to know and do different things to play Chess than you do to play Tag, for example, or to play Digital Zoo than to play The Pandora Project. Every game is about some kinds of situations in some kind of simulated world and therefore not about others. And thus to play any game well, you have to learn to care about the kinds of things that matter in the game. A game may start out being about something you like, but any good game ends up by making you value what you are doing and how you are doing it. Any game that you are willing to keep playing has to do that.

In other words, games begin with players' interests—some thing or things they value-but transform those interests, making them stronger, or weaker, or more narrow, or more focused, or somehow more complex as players take on the values needed to master the game. Games thus embody some of the ideas about learning popularized by one of the giants of progressive education, John Dewey.

\section{JOHN DEWEY}

John Dewey founded the Chicago Laboratory School in 1896 as a response to problems he saw in the industrial school system that had been developed in the 
United States in the last half of the nineteenth century. By 1904 the school was the most innovative experiment in education in the country, and the ideas of progressive education Dewey explored there would inspire educational innovation, policy, and theory for the next century.

The typical caricature of progressive education is that progressives believe children should be free to learn by exploring their own interests. Dewey agreed that children are full of what he called "ideas, impulses, and interests." Indeed, Dewey argued that finding interests is easy. "The child," he wrote in School and Society, "is already intensely active, and the question of education is the question of taking hold of his activities, of giving them direction." The challenge, Dewey claimed, was to take these impulses and use them to lead the child "to larger fields of investigation and to the intellectual discipline that is the accompaniment of such research." 10

The process of moving from interest to understanding, according to Dewey, was learning by doing-or, to be more precise, learning by trying to do something, making mistakes, and then figuring out how to fix them. "If the [child's] impulse is exercised, utilized," Dewey wrote, "it runs up against the actual world of hard conditions to which it must accommodate itself; and there again come in the factors of discipline and knowledge." For example:

Take ... the little child who wants to make a box. If he stops short with the imagination or wish, he certainly will not get discipline. But when he attempts to realize his impulse, it is a question of making his idea definite, making it into a plan, of taking the wood, measuring the parts needed, giving them the necessary proportions, etc. There is involved the preparation of materials, the sawing, planning, the sandpapering, making all the edges and corners to fit. Knowledge of tools and processes is inevitable. ${ }^{11}$

If this process sounds familiar-perhaps recalling Rick and Carl in Digital Zoo or Hallie in Escher's World-it is because this kind of learning by overcoming obstacles is the foundation of all of learning by doing. Summarizing the process in Art as Experience, Dewey wrote:

Impulsion from need starts an experience that does not know where it is going; resistance and check bring about the conversion of direct forward 
action into re-flection; what is turned back upon is the relation of hindering conditions to what the self possesses as working capital in virtue of prior experiences. As the energies thus involved re-enforce the original impulsion, this operates more circumspectly with insight into end and method. Such is the outline of every experience that is clothed with meaning. ${ }^{12}$

Dewey's point is an important one, and the center of any progressive view of education: We learn by trying to accomplish some goal in the face of obstacles. When we bump into an obstacle, we have to step back and try to figure out what we know—and what else we need to know-to help us get past it. Of course, if there is nothing we are trying to do, then when we bump into an obstacle, we just give up, which is why we have to be doing something we care about.

\section{PUSH BACK}

The result is a somewhat curious state of affairs. We learn best when working on things that are neither too easy nor too hard-a psychological state that researcher Mihaly Csikszentmihalyi describes as flow. ${ }^{13}$ If there are no obstacles, we don't learn much. If there are too many, we don't get anywhere, and give up. But this balance works only if, as Dewey put it, "the adverse conditions bear intrinsic relation to what they obstruct instead of being arbitrary and extraneous." 14 That is, the obstacles have to be relevant to the thing you are trying to do: They have to push back on issues that are related to the task at hand, rather than being something irrelevant or extraneous that you have to overcome in order to keep working.

Dewey was not talking about learning math by playing a board game where you have to answer questions about math facts in order to move your piece. He was talking about the kind of learning we see in The Pandora Project, when players have to conduct research about immunology and learn to conduct a mutual gains conflict assessment in order to find a negotiated settlement for clinical trials in xenotransplantation. The obstacles are the needs, desires, and objections of the other players, and in the game those obstacles are overcome by thinking and acting like a negotiator trying to get the best settlement for a client. One player 
summed up quite nicely how Dewey's model of learning by overcoming obstacles in pursuit of a meaningful goal applied in the game: "In order to do it right, you had to look at everything from everybody's point of view—but you had a very definite angle on it."

The fact that people learn this way makes it clear why it is so important that educational experiences develop values as well as skills and knowledge: This kind of learning requires that you care about what you are doing. You have to care enough to persist in doing it in the face of obstacles significant enough that overcoming them leads to real learning.

Dewey's ideas about learning have been influential for a long time, so perhaps it comes as no surprise that some educators are interested in games because they can be used to create progressive learning environments where young people learn by doing things they are interested in. But it is not clear that doing so by copying Dewey's ideas directly would work so well. After years of trying, his model of learning has been implemented in only in a relatively limited way. Only the rarest of classrooms is modeled on Dewey's Laboratory School, where cooking was the basis for much of the science taught and children built their own miniature iron smelters. ${ }^{15}$ While epistemic games do build on Dewey's ideas, they go beyond his vision of progressive education in at least two significant ways.

\section{IT'S A HARD KNOCK (VIRTUAL) LIFE}

Dewey's model of learning through active engagement in meaningful activity (and all of progressive pedagogy that follows his work) depends on the medium in which activity takes place- that is, on the tools and materials with which the student is working. The "obstructions" that a student encounters in trying to achieve some goal lead to learning only if, in Dewey's inimitable turn of phrase, they "bear intrinsic relation to what they obstruct instead of being arbitrary and extraneous." This matters because using traditional materials, such as Cuisenaire Rods, it is relatively easy to capture essential properties of objects in the world, such as shape, number, or color. ${ }^{16}$ Complex social and technical concepts, however-ratio, feedback, or social justice-are harder to "build" into traditional media. Put another 
way, traditional materials do a good job of representing elements of children's mental universe when they are in Piaget's stage of concrete operations, thinking about the observable properties of objects. It is harder to represent abstract ideas of Piaget's more advanced, formal operational stage of thinking without a computer.

But complex social and scientific concepts are quite easy to build into the simulated world of a computer or video game. The virtual worlds of Digital Zoo, Escher's World, The Debating Game, and The Pandora Project are worlds in which players act using complex concepts of locomotion, mathematics, historical interpretation, biotechnology, and ethics using the tools and practices of engineering, graphic design, parliamentary debate, and negotiation. Computer-based games expand the range of what players can realistically do-and thus the worlds they can inhabit and obstacles they can overcome.

As players express their intentions in the virtual world of the game, their understanding runs up against a simulated "world of hard conditions" of the kind that the Dewey suggested was essential to learning. While the scope of virtual worlds is certainly not endless—at least with current technologies—games make it possible for players to participate in activities that are hard, or even impossible, to do with traditional materials.

We know, for example, that in the virtual and cyber worlds that computers make possible, young people can develop new mathematical proofs, collect and analyze scientific data, publish work on the Internet, run a political campaign, or manage a city—not to mention reenact world history or steal a car. ${ }^{17}$

Of course, virtual worlds are not necessarily better than activities in the real world. It might be more effective to participate in a real election for student body president instead of a simulation of an election. The issues being debated would be those that directly affect students' lives. But working in the real world has disadvantages too. Compare, for example, an election for student body president to a simulation of an election for President of the United States in the game The Political Machine. Student elections take longer. They address a narrower range of issues. Not as many students can run a real campaign as can play the game. And in the case of The Political Machine, the knowledge gained in the game (about the electoral college, fundraising, and advertising) applies more directly to conditions that students will encounter outside of school than what happens in most student government elections. 
Computer and video games make it possible for more people to learn about the world by participating in a wider range of meaningful activities than is possible with traditional materials alone. Epistemic games thus go beyond traditional progressive education because they make it possible to extend progressive pedagogies into new realms. But epistemic games also go beyond traditional progressive education because they are epistemic: That is, they are explicitly about epistemology.

\section{SCIENCE, SCIENCE EVERYWHERE}

For Dewey, the result of overcoming obstacles in the pursuit of valued ends was a particular kind of knowledge: It was scientific. It was knowledge that, as Dewey explained, "replaces the repeated conjunction or coincidence of separate facts by discovery of a single comprehensive fact" based on "observations formed by variation of conditions on the basis of some idea or theory." ${ }^{18}$ For example, Dewey explained at great length how cooking an egg (an activity designed to make "a transition from the cooking of vegetables to that of meats") could be a point of departure for such systematic "experimental work":

In order to get a basis of comparison they first summarized the constituent food elements in the vegetables and made a preliminary comparison with those found in meat.... They found that starch and starchy products were characteristic of the vegetables ... and that there was fat in both—a small quantity in vegetable food and a large amount in animal. They were prepared then to take up the study of albumen as the characteristic feature of animal food, corresponding to starch in the vegetables.... They experimented first by taking water at various temperatures... and ascertained the effect of the various degrees of temperature on the white of the egg. That worked out, they were prepared not simply to cook eggs, but to understand the principle involved in cooking eggs. ${ }^{19}$

Dewey was not suggesting that everything we do follows the "Scientific Method" that most children learn about in school: the steps that scientists supposedly follow in advancing formal hypotheses, designing experiments, and drawing conclusions based on the results. Nor did he think that children should 
learn only science. For Dewey, disciplines such as history, geography, and literature were critical to the process of education. They were "tools which society has evolved in the past as the instruments of its intellectual pursuits." ${ }^{20}$ But he believed they are all scientific in the sense that they are all based on propositional understanding-discovering general laws or principles-from conducting experiments. For example, Dewey explained the value of studying the history of "primitive life" primarily as a kind of scientific experiment:

Recourse to the primitive may furnish the fundamental elements of the present situation in immensely simplified form.... We cannot simplify the present situations by deliberate experiment, but resort to primitive life presents us with the sort of results we should desire from an experiment. Social relationships and modes of organized action are reduced to their lowest terms. ${ }^{21}$

Leaving aside the outdated idea that life in the past was a simplified version of modern societies, Dewey was describing historical inquiry as a process of formal experimentation: history as a form of social science rather than a distinct way of knowing. Compare his description of history, for example, to Wineburg's:

A detail is first remembered, but the historian cannot remember its source. This recognition sends the historian searching for the sources of this detail, and, when reunited with its author, the detail is rejected. The reason is that the historian knows that there are no free-floating details, only details tied to witnesses. ${ }^{22}$

For Dewey, when we try to accomplish goals, obstacles push back on us. Overcoming these obstacles pushes us toward scientific understanding of the work we are doing. Or, as Dewey wrote: the "scientific method is the only authentic means at our command for getting at the significance of our everyday experiences of the world in which we live." ${ }^{3}$

\section{NOT JUST SCIENCE EVERYWHERE}

It is certainly true that innovators always conduct experiments of one form or another: the cycles of action and reflection that Schön describes in his studies of 
professional practice. But as Schön points out, this general process of thinking tells us little about how professionals understand the world unless we look more closely at the epistemology that guides that experimentation. It may be true in principle that all knowledge comes from experience, but the pedagogical issue is that different kinds of knowledge are created through different kinds of experiences.

My point is not to suggest that Dewey was wrong or mistaken. But computer and video games let young people think and act in more ways than were possible before. They make it possible for people of all ages to act in virtual worlds whose obstacles push back on social, technological, and conceptual issues far more complex than those that can be simulated using traditional materials alone.

In an epistemic game, those obstacles can push players toward scientific thinking, to be sure. But they can also push players toward other kinds of innovative thinking: into the arms of a professional community and into the kinds of reflection that structure professional learning.

We know a lot about how people become innovative thinkers because we know a lot about how professionals develop their ways of thinking and acting. Epistemic games create virtual worlds that push players into dilemmas that can be resolved only by developing the skills, knowledge, epistemology, and values that guide innovative thinking.

Not all innovative thinking, in other words, is most effectively characterized as scientific. There are a many ways of knowing — many epistemologies— that characterize meaningful, socially, culturally, and economically valuable ways of acting in the world.

\section{MOTIVATION}

In postprogressive epistemic games, players learn to care about the kind of problems that face doctors, lawyers, architects, engineers, journalists, and other innovative professionals and to develop the skills, knowledge, and ways of thinking that are used to solve such problems. That process means hard work, and a lot of it. It is rigorous, because the professions that shape innovative thinking demand rigorous thinking. There are high standards, and rightly so, because by 
definition a professional works in complex situations: situations that require judgment and autonomy — and thus trust. The training of professionals, when it is done well, is about standards of behavior and expectations for results. It is about sophisticated skills, specialized knowledge, guiding norms, and the epistemology that ties them together.

But as we've seen, games based on the training of professionals_-high standards, hard work, and all_-are fun, for two reasons. First, part of the fun of any game is playing by the rules, and the rules of many games are even more complex and demanding than the norms and practices of a profession. The rules of many games children like, such as $\mathrm{Yu}-\mathrm{Gi}-\mathrm{Oh}$, are extremely complex-too complex, in fact, for many adults to play. And, of course, we know that many games require a lot of hard work. In fact, all of the best ones do.

But more than that, adolescents in middle and high school are trying to find their place in the world. They are trying to understand who they are, who they want to be, and how the world works as they move outside of the protective arms of their parents and families. Developmental psychologist Robert Kegan describes the process as developing a "capacity for independence; self-definition; assumption of authority; [and] exercise of personal enhancement, ambition, or achievement." ${ }^{24}$ Studies by Csikszentmihalyi and his colleagues show that adolescence is a period when young people are learning the patterns of participation in society. Csikszentmihalyi's work demonstrates that this learning process requires developing a sense of discipline, and that adolescents are willing to participate in activities when they believe that goals are worthwhile and their actions have meaning. Csikszentmihalyi argues that "intrinsically rewarding learning produces an experience of growth and of mastery, a feeling that the person has succeeded in expanding her or his skills." 25

In other words, adolescents are fascinated by efficacy: the things they can do in the world and the sense of their own power that comes from being able to make things happen. An epistemic game gives players a chance to see how the world-or at least some piece of it-works. It gives them a chance to experience their own efficacy in the face of complex problems by showing them what it is like to be one of the people who makes decisions that shape the world around them. An epistemic game pulls back the curtain and shows players some of the mechanisms of power. 
If efficacy is the hook, the thing that gets players to start the game-if players enjoy an epistemic game at first because they are being taken seriously and given a chance to do the kinds of things that really matter in the worldthen what keeps them in the game is the structure of the practicum itself. Part of what any professional practicum has to do is help create the values of the profession. You can't be a professional unless you care about the things that a professional cares about, and thus professional training has to develop professional skills, knowledge, and epistemology in the context of professional values.

Epistemic games are thus a potentially important part of children's development. Based on his extensive investigations of knowledge work and knowledge workers, business analyst Thomas Davenport argues that personal commitment is an essential part of all innovative thinking. You can do standardized work as an automaton, but innovation requires engagement with the tasks at hand. You have to care about what you are doing. ${ }^{26}$ And in most professions, caring about what you are doing means stepping outside yourself and seeing things as others see them: stakeholders, the public at large, or some specific client. It means shifting focus away from what is interesting to you and toward what matters to others.

This kind of decentering is an essential part of growing up. Children need to shift from thinking exclusively about their own needs and interests to reflecting on and respecting the needs and interests of others. As developmental psychologist Erik Erikson explains, becoming an adult means "taking a place in society at large and caring." 27

Epistemic games thus fulfill young people's basic need to make things happen in a positive and constructive way. In this sense they go beyond what Max's mother was doing in creating an island of expertise. These games are fun because they let players think and act like professionals who care about doing things that matter not just to themselves, but to others in the world.

To be clear: these games are not about becoming professionals, no more than the chores students were doing at the farm school in Vermont were about becoming organic farmers. The goal of epistemic games is not to train players to be doctors, nurses, therapists, lawyers, architects, graphic designers, engineers, negotiators, debaters, urban planners, business leaders, plumbers, carpenters, contractors, or any of a host of socially valued and socially valuable professions. Rather, by playing a game based on the things professionals do in training, 
players can learn to think in innovative ways — and to care—about a wide range of complex and important problems and situations.

But if players in an epistemic game don't become professionals, then what do they become? To answer that question, the next chapter looks at the profession of journalism, and at an epistemic game based on the training of journalists.

\section{For Parents, Teachers, and Mentors}

The Pandora Project is not readily available for use in classrooms, but there are some commercial games that can help players develop professional values in important ways. One such game is A Force More Powerful, which was designed as a teaching tool for nonviolent activists. In the role of chief strategist in a nonviolent movement, players direct the movement's resources, recruit members, and build and break alliances. In the process, they learn about strategic planning, the formulation of objectives, and the development of tactics to meet those objectives. They also come to understand how nonviolent conflict works: the mechanisms and functions of disruptive actions such as strikes, boycotts and mass protests. The game models more than 80 different forms of nonviolent action. Through these scenarios based on real grassroots movements around the world, players learn how fear and enthusiasm work to suppress and motivate recruiting and the value of mobilizing ordinary people to take action.

But whether A Force More Powerful is the best example of a game that can develop professional values is less important than recognizing that the values that players develop in a game matter:

$\rightarrow$ Values matter more than interests. Try to find games that transform existing interests into some form of lasting values rather than just reinforce them.

$\rightarrow$ It may seem like an obvious point, but seek out games about things that matter in the world and that focus on understanding and dealing with the perspective of others. 
$\rightarrow$ Be explicit about the values in a game. Talk about the ethical implications of decisions in the game-and about how those values would or would not be appropriate in situations outside the game.

$\rightarrow$ Perhaps most important, especially with younger children: Don't be afraid to stand up for the values you believe in. Just as there are books that are not appropriate for young children to read, the same is true of games. Make informed decisions about what games your kids play. Once again, one of the best ways to do that is to play them yourself. 